\title{
Case report on energy drink consumption among Health Sciences University students in Gauteng Province, South Africa
}

\author{
Lucy Fernandes ${ }^{*}$, Kebogile Mokwena and Busisiwe Ntuli
}

\author{
* Correspondence: lucy.fernandes@ \\ smu.ac.za \\ Department of Public Health, Sefako \\ Makgatho Health Sciences \\ University, P.O. Box 215, Medunsa \\ 0204, Pretoria, South Africa
}

\begin{abstract}
Background: There are claims that energy drink (ED) consumption can bring about an improvement in mental functioning in the form of increased alertness and enhanced mental and physical energy. These claims address the lifestyle of a student of sleep deprivation and academic pressure with ED consumption becoming a popular practice amongst students. The study's objectives were to determine the prevalence, reasons for, and patterns of ED and alcohol mixed with ED (AmED) consumption amongst university students.
\end{abstract}

Case presentation: Registered students of the Health Sciences University, Gauteng Province, South Africa, formed the study population where this quantitative crosssectional survey conveniently collected data by means of previous validated selfadministered questionnaires from 490 students representing the diverse demographics of the university. Questions on the socio-demographic profile of the participants; pattern of alcohol use; reasons, pattern, and preferred types of EDs use; and the pattern, reason, and experience of AmED use during the past 12 months were asked. Frequency and percentages of distributions were determined, and the possible factors contributing to ED consumption were computed using the chisquare test. Results indicated that a total of $58 \%$ of students were consuming EDs mainly to stay awake (31\%), to be more alert (14\%), and to help with concentration (15\%), 69\% were consuming alcohol, and 16\% were consuming AmEDs.

Conclusion: There is an urgent need for an appropriate public health prevention intervention so that ED consumers can make informed choices when indulging in these health behaviors before the seemingly harmless consumption of ED amongst students becomes a public health issue.

Keywords: Energy drink, Energy drink mixed with alcohol, Students

\section{Background}

Globally, the consumption of energy drinks (EDs) has gained popularity since the 1997 debut of Red Bull@ [1]. In South Africa, EDs also form a fast-growing segment of the soft drink market where figures are indicating that between 2009 and 2014, the annual volume of sports and EDs sold rose from 97.7 million liters to 167.7 million liters, a

(c) The Author(s). 2020 Open Access This article is licensed under a Creative Commons Attribution 4.0 International License, which permits use, sharing, adaptation, distribution and reproduction in any medium or format, as long as you give appropriate credit to the original author(s) and the source, provide a link to the Creative Commons licence, and indicate if changes were made. The images or other third party material in this article are included in the article's Creative Commons licence, unless indicated otherwise in a credit line to the material. If material is not included in the article's Creative Commons licence and your intended use is not permitted by statutory regulation or exceeds the permitted use, you will need to obtain permission directly from the copyright holder. To view a copy of this licence, visit http://creativecommons.org/licenses/by/4.0/. The Creative Commons Public Domain Dedication waiver (http://creativecommons.org/publicdomain/zero/1.0/) applies to the data made available in this article, unless otherwise stated in a credit line to the data. 
rise of approximately 2 to 3 liters per capita in only 5 years [2]. In South Africa, EDs are easily accessible and freely available in shops and is even sold on the crossroads by street vendors with the most common brands of EDs available being: Monster@, Play®, Red Bull@, Full@, Mother $\odot$, Wired $\odot$, Energade $\odot$, MoFaya $\odot$, and Reboost $\odot$ [3].

The main ingredients of EDs (depending on the brand) include guarana, caffeine, ginseng, and small amounts of theophylline, tannins, taurine, and sugar [4]. It is important to note that EDs, where the key ingredient is caffeine, is not the same as sports drinks. By consuming EDs, the central nervous system is stimulated while sports drinks replace chemicals lost during sweating enabling a person to sustain physical activity for longer periods [5]. For the purpose of this study, an energy drink was defined as a "non-alcoholic beverage" marketed as boosting energy levels.

The consumption of the perceived, relatively harmless, EDs has become a public health concern [6-8]. The effects of caffeine are dose-related, with low to moderate doses of caffeine (20 to $200 \mathrm{mg}$ ) resulting in increased happiness, energy, alertness, and sociability [9] with no adverse health effects $[10,11]$. While at higher doses (1000-1500 mg per day), caffeine is also a potent stimulant which could lead to the potential of caffeine intoxication and caffeine dependence [12]. Due to the variation in the amounts of caffeine in EDs and the inadequate product labeling, the likelihood of caffeine overdose is a reality which can be medically problematic [9]. Caffeine intoxication is characterized by headaches, sleep disorders, restlessness, tiredness and irritation, excitement, elevated blood pressure, incoherent and excited thoughts, and speech [1, 10, 12-15]. If caffeine intake is not properly monitored, it could lead to possible dependence accompanied by possible side effects and even harmful withdrawal symptoms $[12,13]$.

Global literature indicates that amongst students, ED consumption has become a very popular practice due to the marketing claims that EDs can bring about an improvement in mental functioning in the form of increased alertness, improved mood, and enhanced mental and physical energy $[1,14,16,17]$. These claims fit in with the fastpaced lifestyle of a student of sleep deprivation and academic pressure [18]. Literature is now suggesting that between $34 \%$ and $80 \%$ of college students have used EDs in the previous month $[1,8,19]$. It is plausible that the excessive consumption of EDs is a marker for high-risk behaviors or may play a role in escalating risk behavior where EDs are used as mixers for alcohol (AmED), for example, Red Bull and vodka or Jägerbombs where a shot of Jägermeister is mixed with a ED [20].

AmED consumption has now become a relatively popular potential health risk behavior and emerging trend among young adults [14, 17, 21,22]. The perceived benefits of AmED consumption are to quicken the onset of intoxication, to reduce fatigue after drinking, and to improve the taste of alcohol [17]. The negative consequences for AmED which may include alcohol dependence, binge drinking, the potential for sexually transmitted infections via high-risk sexual behavior, and substance use is well documented $[8,17,23]$. In part, the reason for AmED is because drinkers experience a different subjective response to the alcohol when drinking it as opposed to a beverage that is not mixed with caffeine and other stimulant ingredients [16].

Despite the potential negative health impacts of ED consumption and the dangers of AmEDs, research on caffeine in South Africa is very limited [24]. A setting, such as a university, is ideal due to the fact that students, of which some can be regarded as young adults, are the group specifically targeted by ED marketing $[25,26]$. 
The aim of this study was to determine the prevalence and patterns of ED consumption amongst university students and determine the proportion of students partaking in AmEDs. Though this study was mainly about ED consumption, individuals with hazardous alcohol use patterns had to be identified in order to determine the prevalence of AmED. By gaining a deeper understanding of the prevalence and extend of ED consumption and the potential harmful practice of AmED amongst the students, this study will inform the development of health education interventions to increase the awareness of students about the potential harmful effects of ED consumption while addressing this emerging public health problem.

\section{Case presentation}

This was a quantitative cross-sectional descriptive case study using a self-administered questionnaire. The setting was the Sefako Makgatho Health Sciences University (SMU) which is a comprehensive health sciences university. Participants were recruited from the five schools within the university, i.e., Medicine, Pharmacy, Health Care Sciences, Oral Health Sciences, and Science and Technology. The university is located in Pretoria, Gauteng Province, South Africa. SMU was established in 2015 and offers various Diploma, Bachelor, Masters, and $\mathrm{PhD}$ programs for undergraduate and postgraduate students.

Data were collected from a convenience sample of 334 undergraduate and 158 postgraduate students out of a total of 5812 registered students for 2018. The undergraduate students were recruited during their participation in an integrated course where all the schools in the university were represented, while the other students were registered for a postgraduate program in Public Health.

The research assistants who collected the data were trained on the study objectives, the ethics of recruitment, and data collection. At the end of the official lecture period, the background and aim of the study were explained by the research assistants and students were also informed that participation was anonymous and voluntary. After agreeing to participate, the students received a self-administered questionnaire which took about $10 \mathrm{~min}$ to complete. Part of the instructions on the question had a statement saying that "by completing this questionnaire, you are consenting to participate in the study." The research assistants collected the questionnaires immediately after completion. The self-administered questionnaire was based on previously validated questionnaires [6, 10, 13] and the Alcohol Use Disorder Identification Test-Consumption (AUDIT-C) [27] (available in the public domain) all covering the topic of alcohol and/ or ED consumption. The questionnaire had four sections.

1) The socio-demographic profiles of the participants: Data were captured by respondents providing their self-reported age and course that they were registered for. Limited options were provided to choose from for the level of study. Students younger than 25 years of age were regarded as "emerging adults" as per international age classification [28].

2) The pattern and type of ED consumed: The pattern was determined by asking how many times and the number of ED drinks per session the participant has consumed during the past 7 days. The options given were "every day," "4-5 times a week," "2-3 times a week," "once a week," and "depending on the need." Options were given to choose from for the types of EDs consumed and the reasons for ED consumption. 
Descriptive statistics, i.e., frequency and percentages of distributions, were determined by using Epi InfoTM.

3) Alcohol use: For the question "How often did you have an alcoholic drink in the past year?" the responses were scored as follows: never ( 0 points), once a month ( 1 point), 2-4 times a month ( 2 points), 2-3 times a week (3 points), 4-5 times a week (4 points), and 6 or more times a week (4 points). For the question "How many alcoholic drinks did you have on a typical day when you were drinking in the past year?" the responses were scored as follows: 0 drinks ( 0 points), $1-2$ drinks ( 0 points), 3-4 drinks (1 point), 5-6 drinks ( 2 points), 7-9 drinks (3 points), and 10 or more drinks (4 points). For the question "How often did you have 6 or more alcoholic drinks on one occasion in the past year?" the point allocated were as follows: never ( 0 points), less than monthly (1 point), monthly ( 2 points), weekly ( 3 points) daily, or almost daily (4 points). The scores for the three questions were added and students could receive a possible score ranging from 0 to 12 . An overall total score of 5 or above was taken as an indication of hazardous or harmful drinking [27].

4) AmED: Participants were given options to choose from for the question on how many days did they have an ED and alcohol on the same occasion and/or in the same drink during the last year. Only those who mix alcohol and EDs were asked to choose between options pertaining to why they engage in this practice and how they felt after consuming AmEDs.

For inferential statistics, the relationship between the independent variable ED consumption, and other variables (gender, level of study, age, and use of alcohol) was computed using the odds ratio, $95 \% \mathrm{CI}$, and chi-square test with bivariate correlation with a $p$ value $<0.05$ considered to be significant.

The necessary institutional ethical clearance and approval was obtained from the Sefako Makgatho Health Sciences University Research and Ethics Committee reference number SMUREC/H/271:2017:IR. Participation was voluntary and anonymous after signing informed consent, and participants received no compensation.

\section{Results}

\section{Demographic description of study participants}

The majority of students were undergraduate (68\%), females (71\%), with $51 \%$ younger than 25 years of age, and in their final year of study (68\%). Presented in Table 1 are the demographic characteristics of the participating students.

\section{Prevalence and pattern of ED use}

The ED consumption patterns are presented in Table 2 with more adults than emerging students consuming EDs (63\% vs 53\%), and the main brands consumed amongst the total population being Red Bull (29\%) followed by Dragon (28\%) which were mainly consumed depending on the need (72\%).

\section{Reasons for ED use}

Participants were given a list of possible reasons to choose from and the self-reported reasons for ED use are presented in Table 3 where $28 \%$ of adult students consumed it to be 
Table 1 Demographic information $(N=490)$

\begin{tabular}{|c|c|c|c|}
\hline & & Frequency & Percentage \\
\hline \multirow[t]{6}{*}{ Age } & $19-24$ & 251 & 51 \\
\hline & $25-30$ & 120 & 25 \\
\hline & $31-36$ & 43 & 9 \\
\hline & $37-41$ & 45 & 9 \\
\hline & $43-49$ & 20 & 4 \\
\hline & $50-56$ & 11 & 2 \\
\hline \multirow[t]{2}{*}{ Gender } & Female & 346 & 71 \\
\hline & Male & 144 & 29 \\
\hline \multirow[t]{2}{*}{ Study level } & Undergraduate & 332 & 68 \\
\hline & Postgraduate & 158 & 32 \\
\hline \multirow[t]{9}{*}{ Degree registered for } & Medicine (MBChB) & 159 & 32 \\
\hline & Nursing Science (BCur) & 34 & 7 \\
\hline & Pharmacy (B Pharm) & 33 & 7 \\
\hline & Occupational Therapy & 32 & 6 \\
\hline & Physiotherapy & 29 & 6 \\
\hline & Human Nutrition and Dietetics & 26 & 5 \\
\hline & Speech Language Pathology \& Audiology & 19 & 4 \\
\hline & Master of Public Health (MPH) & 120 & 25 \\
\hline & Postgraduate Diploma in Public Health (PGDPH) & 38 & 8 \\
\hline \multirow[t]{4}{*}{ Year of study } & 1st year & 104 & 21 \\
\hline & 2nd year & 55 & 11 \\
\hline & 4th year & 173 & 36 \\
\hline & 6th year & 158 & 32 \\
\hline
\end{tabular}

more alert versus the $2 \%$ amongst emerging adults. Adult students were also hoping that they will perform better in the exam ( $8 \%$ vs $3 \%$ amongst emerging adults).

\section{Prevalence and pattern of alcohol and AmED consumption}

Presented in Table 4 are the results for the patterns of ED consumption, alcohol consumption, and AmED consumption with $76 \%$ of participants who were drinking EDs also drinking alcohol without mixing, $16 \%$ were mixing the two, and $7 \%$ of participants consuming alcohol were exposed to hazardous or harmful drinking.

\section{Reasons, feelings, and risky behavior after consuming AmED}

Presented in Table 5 are the reasons for consuming AmED, the experiences after the consumption of AmED, and the reported risky behaviors after the consumption of AmEDs.

The main reason for AmED was to stay awake (26\%) and to feel less tired (20\%) with 32\% feeling full of energy after consumption. The minority (4\%) were involved in unprotected sex or could not remember the incident, while $8 \%$ were using illicit drugs for recreational purposes.

\section{Possible factors related to ED consumption}

The results of the chi-square analysis are presented in Table 6 indicating that alcohol use and age were some of the possible factors related to ED consumption. 
Table 2 ED consumption patterns

\begin{tabular}{|c|c|c|c|c|c|c|}
\hline & \multicolumn{2}{|c|}{$\begin{array}{l}\text { Emerging adult } \\
(\boldsymbol{n}=251)\end{array}$} & \multicolumn{2}{|c|}{ Adult $(\boldsymbol{n}=239)$} & \multicolumn{2}{|c|}{ Total population $(\boldsymbol{N}=490)$} \\
\hline & Frequency & $\%$ & Frequency & $\%$ & Frequency & $\%$ \\
\hline \multicolumn{7}{|c|}{ Consume energy drinks } \\
\hline Yes & 134 & 53 & 151 & 63 & 285 & 58 \\
\hline No & 117 & 47 & 88 & 37 & 205 & 42 \\
\hline \multicolumn{7}{|l|}{ Number per typical sitting } \\
\hline One & 118 & 88 & 137 & 91 & 255 & 90 \\
\hline Two & 14 & 10 & 13 & 9 & 27 & 9 \\
\hline Three or more & 2 & 2 & 1 & & 3 & 1 \\
\hline \multicolumn{7}{|l|}{ Number of times consumed in the past 7 days } \\
\hline Every day & 2 & 2 & 3 & 2 & 5 & 2 \\
\hline 4-5 times a week & 15 & 11 & 20 & 13 & 35 & 12 \\
\hline 2-3 times a week & 10 & 7 & 11 & 7 & 21 & 7 \\
\hline Once a week & 6 & 5 & 13 & 9 & 19 & 7 \\
\hline Depends on the need & 101 & 75 & 104 & 69 & 205 & 72 \\
\hline \multicolumn{7}{|l|}{ Brands of ED consumed* } \\
\hline Red Bull (80 mg caffeine/can) & 39 & 29 & 44 & 29 & 83 & 29 \\
\hline Dragon (180 mg caffeine/can) & 39 & 29 & 40 & 26 & 79 & 28 \\
\hline Reboost Power Play (80 mg caffeine /can) & 32 & 24 & 35 & 23 & 67 & 24 \\
\hline Monster (80 mg caffeine/can) & 22 & 16 & 34 & 23 & 56 & 20 \\
\hline Vitamin Water (2.5 mg/100 ml) & 14 & 10 & 22 & 15 & 36 & 13 \\
\hline
\end{tabular}

*Some students were consuming up to seven different types of EDs

Table 3 Participants self-reported reasons for ED use

\begin{tabular}{|c|c|c|c|c|c|c|}
\hline \multirow[b]{2}{*}{ Reason for ED consumption" } & \multicolumn{2}{|c|}{$\begin{array}{l}\text { Emerging adult } \\
(\boldsymbol{n}=251)\end{array}$} & \multicolumn{2}{|c|}{ Adult $(\boldsymbol{n}=239)$} & \multicolumn{2}{|c|}{$\begin{array}{l}\text { Total population } \\
(\boldsymbol{N}=490)\end{array}$} \\
\hline & Frequency & $\overline{\%}$ & Frequency & $\%$ & Frequency & $\%$ \\
\hline To stay awake & 77 & 31 & 76 & 32 & 153 & 31 \\
\hline Helps to concentrate during study & 37 & 15 & 37 & 15 & 74 & 15 \\
\hline To be more alert & 5 & 2 & 66 & 28 & 71 & 14 \\
\hline To compensate for insufficient sleep & 22 & 9 & 34 & 14 & 56 & 11 \\
\hline It gives long-lasting energy all day & 24 & 10 & 31 & 13 & 55 & 11 \\
\hline Like the taste & 22 & 9 & 30 & 13 & 52 & 11 \\
\hline It quenches thirst & 17 & 7 & 21 & 9 & 38 & 8 \\
\hline It makes the user feel refreshed & 18 & 7 & 16 & 7 & 34 & 7 \\
\hline Helps with better performance in the exam & 8 & 3 & 19 & 8 & 27 & 6 \\
\hline It gives an instant energy rush & 14 & 6 & 9 & 4 & 23 & 5 \\
\hline It replenishes electrolytes after exercise & 8 & 3 & 14 & 6 & 22 & 4 \\
\hline Curiosity & 8 & 3 & 8 & 3 & 16 & 3 \\
\hline To enable a person to enjoy an all-night party & 4 & 2 & 8 & 3 & 12 & 2 \\
\hline Makes user feel healthy & 5 & 2 & 4 & 2 & 9 & 2 \\
\hline To feel better after a hangover & 3 & 1 & 4 & 2 & 7 & 1 \\
\hline
\end{tabular}

"Students could respond to all reasons applicable to them 
Table 4 Patterns of ED, alcohol, and AmED consumption

\begin{tabular}{|c|c|c|c|c|c|c|}
\hline \multirow[b]{2}{*}{ Consumption } & \multicolumn{2}{|c|}{$\begin{array}{l}\text { Emerging adult }(\boldsymbol{n}= \\
\text { 251) }\end{array}$} & \multicolumn{2}{|l|}{$\begin{array}{l}\text { Adult }(\boldsymbol{n}= \\
\text { 239) }\end{array}$} & \multicolumn{2}{|c|}{$\begin{array}{l}\text { Total population }(\boldsymbol{N} \\
=490)\end{array}$} \\
\hline & Frequency & $\%$ & Frequency & $\%$ & Frequency & $\%$ \\
\hline Drinking EDs & 134 & 53 & 152 & 64 & $286 / 490$ & 58 \\
\hline Drinking alcohol & 161 & 64 & 179 & 75 & $340 / 490$ & 69 \\
\hline Drinking ED and alcohol but no mixing & $97 / 134$ & 72 & $121 / 152$ & 79 & $218 / 286$ & 76 \\
\hline AmEDs & $25 / 134$ & 19 & $21 / 152$ & 14 & $46 / 286$ & 16 \\
\hline Hazardous/harmful alcohol consumption \$ & $12 / 161$ & 7 & $12 / 179$ & 7 & $24 / 340$ & 7 \\
\hline Hazardous/harmful alcohol consumption\$ + EDs & $12 / 12$ & 100 & 10/12 & 83 & $22 / 24$ & 92 \\
\hline No ED and no alcohol & $79 / 251$ & 31 & $50 / 239$ & 21 & $129 / 490$ & 26 \\
\hline
\end{tabular}

${ }^{\S}$ According to Alcohol Use Disorder Identification Test-Consumption (AUDIT-C)

\section{Discussion}

The university environment is a distinct setting for the use of EDs due to market claims of increased alertness and enhanced mental and physical energy [14]. These claims of temporary benefits hold the promise of assisting students to study which could lead to better academic performance [25]. Research within college populations suggests that between $34 \%$ and $58 \%$ of college students use energy drinks [1, 8, 25]. Amongst the

Table 5 Reasons, feelings, and risky behavior after consuming AmED ( $N=50)$

\begin{tabular}{|c|c|c|}
\hline & Frequency & Percentage \\
\hline \multicolumn{3}{|l|}{ Reasons for mixing EDs with alcohol } \\
\hline To stay awake & 13 & 26 \\
\hline User feel less tired & 10 & 20 \\
\hline To hide the flavour of alcohol & 10 & 20 \\
\hline User like the taste of AmED & 10 & 20 \\
\hline User can drink more and don't feel so drunk & 8 & 16 \\
\hline User need more energy in general & 7 & 14 \\
\hline The mix can treat or cure a hangover & 5 & 10 \\
\hline User enjoy the effects of the mix & 4 & 8 \\
\hline Other reason/s & 3 & 6 \\
\hline \multicolumn{3}{|l|}{ Feeling after consuming AmEDs } \\
\hline Was full of energy & 16 & 32 \\
\hline There was no difference & 7 & 14 \\
\hline Had trouble sleeping/insomnia & 5 & 10 \\
\hline Had stomach pain/stomach irritation & 2 & 4 \\
\hline Heartbeat was irregular/racing heart & 2 & 4 \\
\hline Had to seek medical help & 2 & 4 \\
\hline Other & 4 & 4 \\
\hline \multicolumn{3}{|l|}{ Unprotected sex after consuming AmED } \\
\hline No & 16 & 32 \\
\hline Yes & 2 & 4 \\
\hline Can't remember & 3 & 6 \\
\hline \multicolumn{3}{|l|}{ Use drugs for recreational purposes } \\
\hline No & 46 & 92 \\
\hline Yes & 4 & 8 \\
\hline
\end{tabular}


Table 6 Possible factors related to ED consumption

\begin{tabular}{llll}
\hline Variable & Odds ratio & $\boldsymbol{p}$ value & $95 \% \mathrm{Cl}$ \\
\hline Gender & 1.0433 & 0.8329 & $0.7037-1.5468$ \\
Use alcohol & 21.7048 & $<\mathbf{0 . 0 0 1}$ & $12.8054-36.7889$ \\
Undergraduate or postgraduate & 1.4080 & 0.8518 & $0.9530-2.0802$ \\
Emerging adult vs adult & 1.5255 & $\mathbf{0 . 0 2 1 9}$ & $1.0623-2.1906$ \\
\hline
\end{tabular}

participants of this study, 58\% reported the consumption of ED during the last week which was in agreement with the prevalence rates reported by similar studies $[9,14$, $25]$. The main reasons for consuming EDs were to stay awake (31\%), to be more alert (14\%), and to help with concentration when studying (15\%) which is similar to other studies [29] where $70 \%$ of students were consuming EDs for vitality and to be more alert (21\%) [11]. A significant difference in ED consumption $(p=0.0219)$ was found between emerging adults, the group specifically targeted by marketing agencies $[25,26]$ and adult students.

Of those who were drinking EDs, $10 \%$ indicated that they were consuming more than one ED per sitting. Although this figure is much less than the $51 \%$ college students surveyed in another study [1], the problem is that the caffeine content of a single ED can range from 80 to $180 \mathrm{mg}$ per can or bottle implying that more than one ED per day (depending on the brand) could potentially pose a health hazard to the consumer due to caffeine overdose [29]. Chronic toxicity due to prolonged exposure at levels greater than 500-600 mg a day [26] can have harmful detrimental physical consequences to the consumer as described before.

Although the main aim of this study was to determine ED consumption, the results of this study indicate that $69 \%$ of the students were consuming alcohol. The only factors related to ED consumption were alcohol consumption $(p \leq 0.001)$ and being younger than 25 years of age $(p=0.0219)$, revealing that those who consume EDs were 21.70 times more likely to also consume alcohol. These results are consistent with previous research supporting a link between caffeine consumption and later alcohol use among adolescents and college students $[9,14,16,23,25]$. But as stated in the literature, the specific nature of the relationship between ED consumption and alcohol consumption cannot be established as the correlations between ED and alcohol consumption do not imply that the one causes the other $[9,16,30]$. Though the thought is that when a person (especially a young person) consumes one beverage that changes how they feel (caffeine) they may be particularly likely to use another beverage that changes how they feel (alcohol) [30]. Due to the fact that only a small number of factors were examined, there is a possibility that other factors that were not tested for could be correlated to ED consumption.

When compared to published literature where it is estimated that between $24 \%$ and $51 \%[1,17,25]$ of college students reported consuming AmED during the past month, the current study finding of $16 \%$ of AmED use is relatively low. This corresponds with a review article [31] aimed to put into perspective the current scientific evidence on the combined use of AmEDs where it was concluded that a relative minority of students take part in the practice of AmEDs. The functional reasons given by the students for the combined use were to feel less tired, to stay awake, and to hide the taste of alcohol, 
while the motivation to get drunk faster and be able to drink more also corresponds with the literature [8]. However, consuming AmEDs is potentially very dangerous as AmED typically contain greater quantities of caffeine, which increases the user's risk of experiencing negative side effects [25]. It is suggested that ED offset the drowsiness associated with alcohol consumption resulting in the user feeling less intoxicated which could lead to the possibility that the user may underestimate their level of intoxication and related impairment [11, 22]. For the user, there is an elevated risk of alcoholrelated injury such as blacking out and alcohol poisoning [22] and the possibility of alcohol dependence as the consumption of AmED beverages has been shown to increase the desire for more alcohol [17]. Consuming AmED is positively associated with binge drinking, and binge drinking increases the risk of acute and chronic alcohol-related problems including risky sexual behaviors $[8,14,22,23]$. Of the $16 \%$ of students that were consuming AmED, 92\% were classified as partaking in hazardous or harmful drinking confirming the association between ED usage and high-risk drinking $[9,11]$.

Furthermore, according to the literature, those who consume AmEDs tend to have a greater involvement in drug use and have higher levels of sensation-seeking, compared with students who do not consume EDs [15]. Eight percent of the participants in the current study who were consuming AmEDs openly admitted that they were using drugs for recreational purposes and 10\% who were consuming AmED engaged in unprotected sex or could not remember if they have used protection during the sexual encounter. Given the high HIV infection rates in sub-Saharan Africa where it is estimated that $19.0 \%$ of adults aged 15-49 is HIV positive [32], unprotected sex has public health implications for the spread of sexually transmitted diseases, including HIV, and unplanned pregnancies $[8,21]$.

\section{Implications}

If the perceived harmless consumption of ED is indeed linked to a greater involvement in alcohol and drug use, then the public health consequences of unregulated EDs that are freely available, might be severe, and pose an important threat to the health of students.

\section{Limitations}

Due to the convenience sampling of students from one health sciences university where their consumption practices could be different than students enrolled in programs not related to health, and the fact that $71 \%$ of the participants were female, generalizations beyond this sample may not be warranted. Despite anonymous participation, the self-report data used in this study may be subjected to social desirability bias as participants may have over or under reported the high-risk sexual behavior and drug use. Due to poor or incomplete memory recall, recall bias could be a factor. Due to the use of cross-sectional data, causal relationships could not be determined. To establish risky behavior, questions related to drug use and unprotected sex were only asked from students who were mixing alcohol and EDs.

\section{Conclusion and recommendations}

In this study, $58 \%$ of the students were consuming EDs mainly to stay awake (31\%), to be more alert (14\%), and to help with concentration when studying (15\%). Sixty-nine percent of students were consuming alcohol and 16\% were consuming AmEDs. 
It is of the utmost importance that students have to be informed about the possible serious negative consequences that are associated with the regular consumption of EDs; warning them about the side-effects and symptoms of caffeine withdrawal and the potential harm they are exposed to when consuming AmEDs which is becoming an increasing popular behavior.

\begin{abstract}
Abbreviations
AmEDs: Alcohol mixed with energy drinks; AUDIT-C: Alcohol Use Disorder Identification Test—Consumption; B Cur: Bachelor of Nursing Science; B Pharm: Bachelor of Pharmacy; EDs: Energy drinks; MBChB: Bachelor of Medicine and Bachelor of Surgery; MPH: Master of Public Health; PGDPH: Postgraduate Diploma in Public Health; SAMRC: South African Medical Research Council
\end{abstract}

\title{
Acknowledgements
}

Not applicable

\section{Authors' contributions}

The authors LF, KM, and BN equally contributed to the development, execution, and write-up of this study. The authors read and approved the final manuscript.

\section{Funding}

The South African Medical Research Council (SAMRC) through the Research Capacity Development program supported the research reported in this publication.

\section{Availability of data and materials}

Please contact corresponding author for data requests.

\section{Ethics approval and consent to participate}

This study received the Institutional ethical clearance and approval from the Sefako Makgatho Health Sciences University Research Committee reference number SMUREC/H/271:2017:IR. All participants signed an informed consent form before participation.

\section{Consent for publication}

Not applicable.

\section{Competing interests}

The authors declare that they have no competing interests.

Received: 26 September 2019 Accepted: 27 April 2020

Published online: 13 May 2020

\section{References}

1. Malinauskas BM, Aeby VG, Overton RF, et al. Survey of energy drink consumption patterns among college students. Nutr J. 2007;6:35. https://doi.org/10.1186/1475-2891-6-35.

2. Stacey N, van Walbeek C, Maboshe M, et al. Energy drink consumption and marketing in South Africa. Prev Med. 2017; 105:S32-6. https://doi.org/10.1186/1475-2891-6-35.

3. Maharaj Y. Does the sports and energy drink market have a 'spring' in its step? Insight Survey. 2016. [Cited 2019 May 15]. Available from: https://www.insightsurvey.co.za/blog/sports-energy-drink-market-spring-step.

4. Gunja N, Brown JA. Energy drinks: health risks and toxicity. Med J Aust 2012;196:46-49. https://doi.org/10.5694/mja11. 10838.

5. Life Education Australia. Sports vs energy drinks. 2019. [Cited 2019 June 11]. Available from: https://www.lifeeducation. org.au/parents/sports-drinks-vs-energy-drinks.

6. Pennington N, Johnson M, Delaney E, Blankenship MB. Energy drinks: a new health hazard for adolescents. J Sch Nurs. 2010;26(5):352-9. https://doi.org/10.1177/1059840510374188.

7. Pomeranz JL, Munsell CR, Harris JL. Energy drinks: an emerging public health hazard for youth. J Public Health Policy. 2013;34(2):254-71. https://doi.org/10.1057/jphp.2013.6.

8. Bonar EE, Cunningham RM, Polshkova S, et al. Alcohol and energy drink use among adolescents seeking emergency department care. J Addict Behav. 2015;43:11-7. https://doi.org/10.1016/.jaddbeh.2014.11.023.

9. Arria AM, Caldeira KM, Kasperski SJ, et al. Increased alcohol consumption, nonmedical prescription drug use, and illicit drug use are associated with energy drink consumption among college students. J Addict Med. 2010;4(2):74-80. https:// doi.org/10.1097/ADM.0b013e3181aa8dd4.

10. Lodato F, Araújo J, Barros H, et al. Caffeine intake reduces sleep duration in adolescents. Nutr Res. 2013;33:726-32. https://doi.org/10.1016/j.nutres.2013.06.005.

11. Reid SD, Ramsarran J, Brathwaite R, et al. Energy drink usage among university students in a Caribbean country: patterns of use and adverse effects. J Epidemiol Glob Health. 2015;5:103-16 https://doi.org/10.1016/j.jegh.2014.05.004.

12. Lee K-H, Human GP, Fourie JJ, et al. Medical students' use of caffeine for 'academic purposes' and their knowledge of its benefits, side-effects and withdrawal symptoms. Fam Pract. 2009;51(4):322-7 https://doi.org/10.1080/20786204.2009. 10873872.

13. Gray B, Das JK, Semsarian C. Consumption of energy drinks: a new provocation test for primary arrhythmogenic diseases? Int J Cardiol. 2012;159:77-8. https://doi.org/10.1016/j.ijcard.2012.05.121. 
14. Azagba S, Lagnille $D$, Asbridge M. An emerging adolescent health risk: caffeinated energy drink consumption patterns among high school students. Prev Med. 2014;62:54-9 https://doi.org/10.1016/j.ypmed.2014.01.019.

15. Leal WE, Jackson DB. Energy drinks and escalation in drug use severity: an emergent hazard to adolescent health. Prev Med. 2018;111:391-6.

16. Marczinski $\mathrm{CA}$, Fillmore MT, Henges $\mathrm{AL}$, et al. Mixing an energy drink with an alcoholic beverage increases motivation for more alcohol in college students. Clin Exp Res. 2013;37(2):276-83. https://doi.org/10.1111/j.1530-0277.2012.01868.x.

17. Snipes DJ, Benotsch EG. High-risk cocktails and high-risk sex: examining the relation between alcohol mixed with energy drink consumption, sexual behavior and drug use in college students. J Behav Addict. 2013;38(1):1418-23. https://doi.org/10.1016/j.addbeh.2012.07.011.

18. Ianni PA, Lafreniere KD. Personality and motivational correlates of energy drink consumption and misuse among female undergraduate students. Personal Individ Differ. 2014;69:110-4. https://doi.org/10.1016/.jpaid.2014.05.022.

19. Costa BM, Hayley A, Miller M. Young adolescents' perceptions, patterns, and contexts of energy drink use. A focus group study. Appetite. 2014;80:183-9. https://doi.org/10.1016/j.appet.2014.05.013.

20. Trapp SA, Allen KL, O'Sullivan T, et al. Energy drink consumption among young Australian adults: associations with alcohol and illicit drug use. Drug Alcohol Depend. 2014;134:30-7. https://doi.org/10.1016/j.drugalcdep.2013.09.006

21. Berger L, Fendrich M, Fuhrmann D. Alcohol mixed with energy drinks: are there associated negative consequences beyond hazardous drinking in college students? Addict Behav. 2013;38:2428-32. https://doi.org/10.1016/j.addbeh.2013. 04.003 .

22. Patrick ME, Maggs JL. Energy drinks and alcohol: links to alcohol behaviors and consequences across 56 days. J Adolesc Health. 2014;54:454-9. https://doi.org/10.1016/j.jadohealth.2013.09.013.

23. Emond JA, Gilbert-Diamond D, Tanski SE, Sargent JD. Energy drink consumption and the risk of alcohol use disorder among a national sample of adolescents and young adults. J Pediatr. 2014;165:1194-200. https://doi.org/10.1016/j.jpeds. 2014.08.050.

24. Persad LA. Energy drinks and the neurophysiological impact of caffeine. Front Neurosci. 2011;5:1-8. https://doi.org/10. 3389/fnins.2011.00116.

25. Velazquez CE, Poulos NS, Latimer LA, Pasch KE. 2012, Associations between energy drink consumption and alcohol use behaviors among college students. Drug Alcohol Depend. 2012;123:167-72. https://doi.org/10.1016/j.drugalcdep.2011. 11.006.

26. Bunting H, Baggett A, Grigor J. Adolescent and young adult perceptions of caffeinated energy drinks. A qualitative approach. Appetite. 2013;65:132-8 https://doi.org/10.1016/j.appet.2013.02.011.

27. Bush K, Kivlahan DR, McDonell MB, et al. KA. The AUDIT alcohol consumption questions (AUDIT-C): an effective brief screening test for problem drinking. Arch Intern Med. 1998;158:1789-95. https://doi.org/10.1001/archinte.158.16.1789D

28. United Nations. Department of International Economic and Social Affairs Statistical Office. Provisional quidelines on standard international age classifications. Statistical papers Series M No.74. [Cited 2020 February 6]. Available from: http://unstats.un.org/unsd/publication/SeriesM/SeriesM_74e.pdf.

29. Marmorstein MR. Investigating associations between caffeinated beverage consumption and later alcohol consumption among early adolescents. Addict Behav. 2019;90:362-8. https://doi.org/10.1016/j.addbeh.2018.11.033.

30. Aluqmany R, Mansoor R, Saad U, et al. Consumption of energy drinks among female secondary school students, Almadinah Almunawwarah, Kingdom of Saudi Arabia. J Taibah Univ Sci. 2013;8(1):60-5. https://doi.org/10.1016/j.jtumed. 2013.01.009.

31. Verster JC, Aufricht C, Alford C. Energy drinks mixed with alcohol: misconceptions, myths, and facts. Int J Gen Med. 2012;5:187-98. https://doi.org/10.2147/IJGM.S29313.

32. Statistics South Africa (STATSA). Mid-year population estimates 2018. [Cited 2019 May 15]. Available from: https://www. statssa.gov.za/publications/P0302/P03022018.pdf.

\section{Publisher's Note}

Springer Nature remains neutral with regard to jurisdictional claims in published maps and institutional affiliations.

Ready to submit your research? Choose BMC and benefit from:

- fast, convenient online submission

- thorough peer review by experienced researchers in your field

- rapid publication on acceptance

- support for research data, including large and complex data types

- gold Open Access which fosters wider collaboration and increased citations

- maximum visibility for your research: over $100 \mathrm{M}$ website views per year

At BMC, research is always in progress.

Learn more biomedcentral.com/submissions 